\title{
BMJ Open The postoperative handover: a focus group interview study with nurse anaesthetists, anaesthesiologists and PACU nurses
}

\author{
Maria Randmaa, ${ }^{1,2,3}$ Maria Engström, ${ }^{1,3,4}$ Christine Leo Swenne, ${ }^{3}$ \\ Gunilla Mårtensson ${ }^{1,3}$
}

To cite: Randmaa M, Engström M, Swenne CL, et al. The postoperative handover: a focus group interview study with nurse anaesthetists, anaesthesiologists and PACU nurses. BMJ Open 2017;7:e015038. doi:10.1136/ bmjopen-2016-015038

- Prepublication history for this paper is available online. To view these files please visit the journal online (http://dx.doi org/10.1136/bmjopen-2016015038).

Received 4 November 2016 Revised 10 April 2017 Accepted 11 May 2017

\section{CrossMark}

${ }^{1}$ Faculty of Health and Occupational Studies, University of Gävle, Gävle, Sweden

${ }^{2}$ Centre for Research and Development, Uppsala University/County Council of Gävleborg, Gävle, Sweden ${ }^{3}$ Department of Public Health and Caring Sciences, Uppsala University, Uppsala, Sweden ${ }^{4}$ Nursing Department, Medicine and Health College, Lishui University, China

Correspondence to

Maria Randmaa; maaraa@hig.se

The study was presented in the thesis Randmaa M, Communication and Patient Safety: transfer of information between healthcare personnel in anaesthetic clinics. Uppsala: Acta Universitatis Upsaliensis 2016. ISBN 978-91-554-94896.

\section{ABSTRACT}

Objectives To investigate different professionals' (nurse anaesthetists', anaesthesiologists', and postanaesthesia care unit nurses') descriptions of and reflections on the postoperative handover.

Design A focus group interview study with a descriptive design using qualitative content analysis of transcripts.

Setting One anaesthetic clinic at two hospitals in Sweden. Participants Six focus groups with 23 healthcare professionals involved in postoperative handovers. Each group was homogeneous regarding participant profession, resulting in two groups per profession: nurse anaesthetists $(n=8)$, anaesthesiologists $(n=7)$ and postanaesthesia care unit nurses $(n=8)$.

Results Patterns and five categories emerged: (1) having different temporal foci during handover, (2) insecurity when information is transferred from one team to another, (3) striving to ensure quality of the handover, (4) weighing the advantages and disadvantages of the bedside handover and (5) having different perspectives on the transfer of responsibility. The professionals' perceptions of the postoperative handover differed with regard to temporal foci and transfer of responsibility. All professional groups were insecure about having all information needed to ensure the quality of care. They strived to ensure quality of the handover by: focusing on matters that deviated from the normal course of events, aiding memory through structure and written information and cooperating within and between teams. They reported that the bedside handover enhances their control of the patient but also that it could threaten the patient's privacy and that frequent interruptions could be disturbing.

Conclusions The present findings revealed variations in different professionals' views on the postoperative handover. Healthcare interventions are needed to minimise the gap between professionals' perceptions and practices and to achieve a shared understanding of postoperative handover. Furthermore, to ensure high-quality and safe care, stakeholders/decision makers need to pay attention to the environment and infrastructure in postanaesthesia care.

\section{INTRODUCTION}

The handover consists of three key aspects: transfer of (1) information, (2) responsibility
Strengths and limitations of this study

To the best of our knowledge, this is the first study investigating nurse anaesthetists', anaesthesiologists' and PACU nurses' views on postoperative handover using focus group interviews.

- Focus group interviews have the advantage of reaching a wider range of views through group interaction than individual interviews.

- A strength of the study was that personnel involved in postoperative handover were interviewed using profession-based groups, the goal being to try to understand each group's perspective on the handover.

- A further strength was that an assistant moderator observed the focus group interviews and all participants agreed on the summary.

- One limitation could be the small sample size drawn from two similar hospitals.

and/or accountability, in (3) the context of teams and their work environments. ${ }^{1}$ With regard to information transfer, studies have shown that anaesthesiologists and postanaesthesia care unit (PACU) nurses had different expectations concerning the content of information transferred ${ }^{2}$ and opinions on what information needs to be reported. ${ }^{3}$ Although the handover consists of transfer of responsibility and/or accountability, one study revealed a lack of consensus among personnel concerning when the transfer of responsibility and/or accountability takes place. ${ }^{4}$ Yet another study showed that, during postoperative handover, the time of transfer of responsibility varied. ${ }^{2}$ Concerning working conditions during postoperative handover, personnel often work in teams that consist of several different professionals working together in an environment characterised by frequent interruptions, ${ }^{256}$ which interfere with the handover recipient's memory. ${ }^{7}$ 
Teamwork is an essential component of achieving high reliability in healthcare, ${ }^{8}$ and working atmosphere and shared understanding are factors of importance to the quality of handover. ${ }^{9}$ Poor surgical teamwork behaviour concerning information sharing during intraoperative and handover phases has been shown to be significantly associated with more frequent postoperative complications or death. ${ }^{10}$

To summarise, postoperative handovers are crucial to patient safety. However, there is a lack of consensus about what constitutes a good handover. ${ }^{11-13}$ A systematic review of postoperative handover by Møller et $a l^{14}$ concluded that it is important to acknowledge the role of communication, teamwork and collaboration within the setting. Furthermore, it is important that different professionals have a shared understanding. ${ }^{9}{ }^{15}$ To achieve such an understanding, it is essential to generate knowledge about each professional group's views on postoperative handover. Thus, there is need to identify whether there are potential gaps between different health professionals' perceptions of postoperative handover that can affect patient safety. Qualitative studies of postoperative handovers between anaesthesiologists and PACU nurses ${ }^{16-19}$ and a mixed methods study ${ }^{20}$ have been conducted. To date, however, no study has investigated anaesthesiologists', PACU nurses' and nurse anaesthetists' views on postoperative handover using profession homogeneous focus group interviews.

\section{Aim}

The aim of the present study was to investigate different professionals' (nurse anaesthetists', anaesthesiologists' and PACU nurses') descriptions of and reflections on the postoperative handover.

\section{METHODS \\ Design}

A qualitative descriptive design was used.

\section{Setting}

The participants worked in an anaesthetic clinic located at two medium-sized hospitals in central Sweden, which share the same top management and are located in the same county council district, with about $130 \mathrm{~km}$ distance between them. In Sweden, postoperative handovers at the PACU between a nurse anaesthetist (the sender) and a specialist nurse in intensive care (the receiver) are common. Nurse anaesthetists may, with support from the anaesthesiologist, independently induce, maintain and conclude general anaesthesia. A specialist nurse in intensive care may judge, address and evaluate medical and nursing interventions. ${ }^{21}$ During the typical postoperative handover, the nurse anaesthetist and PACU nurse stand nearby the patient while looking at the written anaesthetic record, the patient and the monitor. On some occasions, a theatre nurse and a licenced practical nurse are also present. Sometimes an anaesthesiologist is present during the postoperative handover or is the person doing the reporting. The written anaesthetic record contains information about the anaesthetic procedure, drugs and fluids given, blood loss, vital parameters and the performed surgery. The electronic patient record, where the patient's clinical background and medication are documented, is located at some distance away from the patient or in another room, that is, not in direct proximity to where most of the postoperative handovers take place. ${ }^{6}$ During the period June 2014 to June 2015, 16004 operations from different specialties (13235 inpatients and 2769 outpatients) were performed at the two hospitals. At the anaesthetic clinic, the communication tool Situation-Background-Assessment-Recommendation $(\mathrm{SBAR})^{22}$ and the WHO Surgical Safety Checklist ${ }^{23}$ were used. The WHO Surgical Checklist was developed to increase teamwork and communication in surgery. The checklist is designed to ensure patient safety on three occasions during the surgical procedure: 'Sign in (before the induction of anaesthesia), 'Time out' (before the incision of the skin) and 'Sign out' (before the patient leaves the operating theatre $(\mathrm{OT})){ }^{23}$

\section{Data collection}

A total of six focus group interviews were conducted from January to May 2015. Purposive sampling was used, and the heads of department established contact with potential participants who had at least 1 year's experience in the profession. The participants received oral and written information about the study, and written informed consent was obtained. Because of the interaction between respondents and the group dynamics, focus group interviews have the advantage of elucidating both individual and shared views on a topic as well as providing rich information. ${ }^{24}$ The homogeneous composition of the groups was based on the participants' similar professions, role and experience of the same issue,${ }^{25}$ the goal being to identify patterns in the professional groups' descriptions of and reflections on postoperative handover. The six focus groups consisted of two groups of nurse anaesthetists, two groups of anaesthesiologists and two groups of PACU nurses. In total, 23 respondents participated (table 1). The study was approved by the Regional Ethical Review Board in Uppsala (reg. no. 2011/061).

A semistructured interview guide was used covering opening questions, introductory questions, transition questions and key questions. The interview guide was pilot-tested on a focus group of PACU nurses in another hospital, and minor changes were made. The focus group interview started with opening questions to get everyone to talk; thereafter, introductory questions were posed to introduce the topic in focus and to encourage conversation among the participants. To move the conversation closer to the key questions, transition questions were posed. ${ }^{24}$ The key questions concerned the participants' descriptions of and reflections on the transfer of information during handover, the transfer of responsibility and/ or accountability and the context of teams and their work environment. One example of a key question is: 'Can 
Table 1 Demographic characteristics of participants

\begin{tabular}{|c|c|c|c|}
\hline Profession & $\begin{array}{l}\text { Gender } \\
\text { Male/female }\end{array}$ & $\begin{array}{l}\text { Median age } \\
(Q 1-Q 3)^{\star}\end{array}$ & $\begin{array}{l}\text { Median years of practice } \\
(\text { Q1-Q3)* }\end{array}$ \\
\hline Nurse anaesthetists & $2 / 6$ & $40(34-44)$ & $3(2-16)$ \\
\hline PACU nurses $\ddagger$ & $0 / 8$ & $59(55-63)$ & $34(23-40)$ \\
\hline
\end{tabular}

${ }^{*}$ Quartiles.

†Years of practice in current profession.

$\ddagger$ Postanaesthesia care unit (PACU) nurses were all specialist nurses in intensive care, which means registered nurses with 1 year of training and a degree in intensive care.

you talk about what kind of information you usually get? '-' What kind you try in particular to focus on and listen to? '-' Why do you focus especially on this information?'. Probes were used to go into more depth on a certain topic. In order to stimulate discussion during the focus group interviews, the participants were also presented with an example from a transcribed verbal handover. ${ }^{24}$ Finally, questions about the ideal handover were asked. In the second part of the focus group interview, the main results of an observational study of postoperative handover ${ }^{6}$ were presented and discussed, but this is not included in the present analysis. All focus group interviews were conducted by one moderator (MR), who is a nurse anaesthetist and specialist nurse in intensive care with 22 years' experience in the professions. During the focus group interviews, the assistant moderator (GM) observed the interaction between participants in the group and made notes. ${ }^{24}$ At the end of the focus group interview, the assistant moderator provided a summary, and concluding questions about the adequacy of the summary were posed to enable participants to reflect back on previous comments. ${ }^{24}$ The focus group interviews lasted 1-1.5 hours; they were held in a quiet room at the participants' workplace and digitally recorded.

\section{Data analysis}

The focus group interviews were analysed inductively, using qualitative content analysis. ${ }^{25}$ The recorded focus group interviews were listened to and transcripts were read and re-read to obtain an overall impression and become familiar with the text. The three professional groups were first analysed separately, according to the study aim, in three steps, the goal being to identify preliminary subcategories. ${ }^{25}$ The steps were: (1) meaning units (sentences and paragraphs) were identified and condensed, abstracted and labelled with a code. (2) The codes were sorted into three topics from the interview guide-information, responsibility and/or accountability-in the context of teams and their work environments. (3) The codes within each topic were grouped into preliminary subcategories. Thereafter, the preliminary subcategories for the three professional groups were put together and compared, and subcategories with similar names were scrutinised and grouped together when found to have the same content. Next, the subcategories were compared for similarities and differences and grouped into five categories. The analyses were primarily carried out by the moderator (MR) and the assistant moderator (GM). During the analysis process, the subcategories and categories were discussed with all coauthors until consensus was reached.

\section{RESULTS}

From the analysis of the nurse anaesthetists', anaesthesiologists' and PACU nurses' descriptions of and reflections on the postoperative handover, five categories emerged: 'Having different temporal foci during handover', 'Insecurity when information is transferred from one team to another', 'Striving to ensure quality of the handover', 'Weighing the advantages and disadvantages of the bedside handover'and 'Having different perspectives on the transfer of responsibility.' Patterns in the three professional groups' descriptions and reflections appeared, and these patterns are described in each of the categories and subcategories (table 2). The quotations are indented and the notional sign '-' marks when another participant, within the group, interjects a comment or continues the discussion.

\section{Having different temporal foci during handover}

The three professional groups reported different temporal foci during the postoperative handover, for example, focusing mainly on the past, on the present and on the continuum of care in its entirety. As senders of information, the nurse anaesthetists focused mainly on what they themselves had done, that is, the anaesthesia process, and partly on the patient's continuing care. They were uncertain concerning which information the PACU nurses considered to be essential and mentioned a disinterest in some of the information reported. The anaesthesiologists reported that they focused on the continuum of care from the operating theatre (OT) to discharge, for example, the surgical procedure, observations and recommendations. They stated that all personnel should focus on the continuity of care, but they were unsure whether that was the case during the reported handover. Like the nurse anaesthetists, the anaesthesiologists were uncertain about the receivers' focus during handover. As receivers of information, the PACU nurses reported focusing mainly on essential information of importance for the 'here and now', for example, which patient was to be taken care of, 
vital parameters and recommendations for conducting postoperative care at the PACU. They related that the nurse anaesthetists' focus was mostly on reporting information about the anaesthesia process.

/.../we often report on how the anaesthesia went, if the patient was stable and such things /.../because that's the main thing for us. '- /.../we report on things we're interested in and they [PACU nurses] have other interests. (Nurse anaesthetists)

It can sometimes be very frustrating, I must say, because some nurses aren't interested in what you have to say. '- - / .../ but that it's difficult, that I don't really know what they're interested in.' '- / /.../ they [PACU nurses] say,"I'm not all that interested in the anaesthesia process, but more in drainage and continued prescription of medications. (Nurse anaesthetists)

Insecurity when information is transferred from one team to another

All professional groups described and reflected on being uncertain as to whether all of the information needed was actually transferred from one team to another. The nurse anaesthetists reported that they were obliged to transfer all important information about the patient from the OT team to the PACU team, but like the anaesthesiologists and PACU nurses, they reported having doubts about whether all of the essential information from the surgeon or theatre nurse was transferred before the patient left the OT. The anaesthesiologists reported insufficient 'sign out' between the main surgeon and the nurse anaesthetist before the patient left the OT and considered this to entail the risk of postoperative misjudgements. They saw improvements in continuity of care if important information was always communicated by the main surgeon before the patient left the OT. Furthermore, the anaesthesiologists felt that several information transfers and lack of knowledge posed potential risks to the patient's continued care.

We don't know a thing about that [catheters, dressings, drainage]. The surgeon often escapes before saying anything $/ \ldots /$. And then we don't have answers to the PACU's questions. (Nurse anaesthetist)

$/ . . . /$ it's up to the team to be clear with each other before they leave the operation theatre and I think there are shortcomings there. The surgeon may have things in mind that aren't conveyed and that I don't comprehend. There are four perspectives that need to become one. (Anaesthesiologist)

/.../And how they coped with the surgery because the others [Nurse anaesthetists] don't have a clue, you know, what it's all about.'-'No, and what they [Surgeons] have done. (PACU nurses)

The nurse anaesthetists also reported insecurity as to whether the information was understood, and the anaesthesiologists reported insecurity about the receiver's knowledge when they did not know the PACU nurse 
involved. Furthermore, the nurse anaesthetists and anaesthesiologists reflected on the need for confirmation, by the receiver, of the information given; thus, they wanted to be sure the information was understood.

/.../So I assume that if I report to PACU and they don't understand what I'm talking about then I really hope they say something and ask, like 'now I don't know what you mean here. $\because-\ldots /$ but sometimes I think they do, though some of them look bewildered. (Nurse anaesthetists)

/.../But I would probably have liked for the person who receives somewhere, for them to summarise and confirm what they have been told. Then I leave and I have made my report but I don't know whether they understood what I wanted. (Anaesthesiologist)

\section{Striving to ensure quality of the handover}

The three professional groups described and reflected on how they strived to ensure quality during the handover by: focusing the information on deviating events, aiding memory through structure and written information and cooperating within and between teams. All of the groups mentioned the importance of emphasising information on matters that deviate from the normal course of events. They reported that information concerning an anaesthetic and surgical process that has proceeded as expected is less important to mention. The nurse anaesthetists and anaesthesiologists also saw the importance of limiting the amount of information during postoperative handover.

$/ \ldots /$ put the focus on that, if it's something unusual/.../that sticks out or if the patient has a medical background that means you have to think a bit differently.'-Yes, I think so too' - 'Yes"-'Yes, things that occur during surgery that are out of the ordinary $-" / \ldots /$ where do we draw the line? '-Exactly '-And of course we do, we make some kind of selection and if there is nothing special, the report will be shorter. (Anaesthesiologists)

And if something special has occurred.'-Yes, with the patient, loss of blood pressure, the pulse increases or something like that, or extraordinary bleeding. Something that they had to do something about, basically. (PACU nurses)

The nurse anaesthetists and the anaesthesiologists reported using a structure such as SBAR to aid memory when they reported essential information. The anaesthesiologists and the PACU nurses expected to receive the information within a structure. The PACU nurses also reflected on the importance of asking questions, in a structured manner, during the entire handover, rather than only at the end of the handover. The nurse anaesthetists and the PACU nurses reflected on the importance of having written information in front of them during handover to aid memory; they felt that the electronic patient records complicated information retrieval, because using them was, in their view, time consuming and caused nurses to lose sight of the patient's condition.

/.../if you follow the SBAR concept, you have a main thread through the whole thing /.../"-'That's what xx says about the main thread, that you find it and thinks that SBAR helps you here. (Nurse anaesthetists)

Yes, if there's anything special there I want to - but what was your thinking there? But we have been taught to ask our questions later and that's.'-'Not easy.'-'There is a risk that you forget since there's a lot going on around you. You should have the opportunity to interrupt, at least once. (PACU nurses)

All professional groups saw the benefits of cooperation. The nurse anaesthetists reflected on the need for improved cooperation within the OT team as well as for developing further collaboration between the OT team and the PACU team to increase interaction around achieving consensus on how handovers should always be carried out. The PACU nurses described the advantages of the theatre nurses and the nurse anaesthetist collaborating during handover, as collaboration meant transfer of more information about the surgical process. However, they also mentioned the disadvantages, in that collaboration of this kind also meant a more unstructured handover. The anaesthesiologists and the PACU nurses reported the benefits of cooperation within the PACU team, which they said facilitated and safeguarded the handover situation.

$/ \ldots /$ need to discuss how we will report and who will do the reporting and what should be reported, and we have to have this discussion among ourselves in the OT and we need have it with the PACU nurses /.../and arrive at some consensus/.../ (Nurse anaesthetist)

\section{Weighing the advantages and disadvantages of the bedside handover}

The professional groups described and reflected on both the advantages and the disadvantages associated with the bedside handover. Nurse anaesthetists and PACU nurses reflected on the benefits of carrying out handovers close to the patient, as this provided control over the patient's medical condition. However, it might threaten the patient's privacy because other patients might hear the report. The nurse anaesthetists described how decisions about whether the handover should be performed bedside depended on whether the information transferred was meant to be heard by the patient. The PACU nurses also reflected on the time-saving benefits of the bedside handover, compared with a handover in a separate room. The anaesthesiologists and the PACU nurses reflected on the disturbing bedside environment, which sometimes entailed frequent interruptions they felt caused stress and distraction. 
When you're standing at the bedside you can check the vital parameters and see that everything is fine when you hand the patient over '-Yes' (Nurse anaesthetists)

$-/ \ldots /$ I prefer having the patient in front of me/.../ The times the nurse anaesthetists come and report on a patient I can't see, that upsets me, because I would really like to see who they're talking about.'-II want to have control. (PACU nurses)

While giving my report/.../if I'm disturbed/.../I mean if my thoughts are interrupted. I think that's dangerous, because every time it happens is harder to return to the main thread. (Anaesthesiologist)

Well, that the machines are beeping and ringing, it gets your adrenalin going, because you're used to reacting to it.'-'Well, then your attention easily shifts to the beeps. '-'That's the way it is. '-'You're disturbed and distracted. And that's the idea, it is a warning signal to us. (PACU nurses)

\section{Having different perspectives on the transfer of responsibility} The professional groups described different perspectives on the transfer of responsibility. The nurse anaesthetists reported that they handed over responsibility when all the information was given to the PACU nurse and when they left the PACU. The anaesthesiologists handed over responsibility to other physicians, but their overall responsibility (accountability) remained even after handover to a PACU nurse. The PACU nurses stated that they required control over the patient's condition before taking over the responsibility. Uncertainty about responsibility arose when the nurse anaesthetist provided incomplete information about the patient or when the nurse anaesthetist failed to complete tasks that he/she was supposed to have done prior to handover.

When you hand information over you include what you know and then the responsibility is someone else's. (Nurse anaesthetists)

We don't transfer the responsibility just because we've transferred the patient.'-'As a medical doctor, you still hold overall responsibility. (Anaesthesiologists)

$/ \ldots /$ you have to wait before taking all of the responsibility, because they should already have found out certain things in the operating theatre/.../but I have to know/.../you have to know what we're going to do with this patient. (PACU nurse)

\section{Observation of interaction during focus group interviews}

During the focus group interviews, the interaction between the participants was observed by the assistant moderator. Overall, the atmosphere in all six focus groups was judged to be friendly. The participants seemed to be familiar with each other and no participant seemed shy or otherwise reluctant to speak. The topic engaged them in a lively discussion and 'postoperative handover' did not seem to be a sensitive topic. Within the groups, no single participant dominated the discussion and each participant had roughly the same amount of time to talk. During the focus group interviews, the participants often confirmed each other's statements non-verbally, for example, by nodding or smiling, and verbally, by completing each other's statements and sentences.

\section{DISCUSSION}

In the present study, the temporal foci differed between the three professional groups. The nurse anaesthetists mainly focused on the past, the anaesthesiologists mainly focused on the continuum of care and the PACU nurses mainly focused on the present, but did report that the nurse anaesthetists' handovers mostly concerned information about the anaesthesia process. This is in line with an earlier study showing that PACU nurses sought information other than that reported by the sender. ${ }^{2}$ A previous study showed that, of the items transferred during postoperative handover, the drugs used during anaesthesia were the items least likely to be remembered by the PACU nurses. ${ }^{6}$ In the present study, the nurse anaesthetists reported feeling that the PACU nurses were not interested in the information transferred. If the sender transfers information concerning the past (ie, the anaesthesia process) that the receiver pays less attention to, because the receiver is focusing on factors important to the continuing care, we can assume that passive listening during handover on the part of the receiver will result in information loss. This is in line with Flin $e t a l,{ }^{26}$ who suggested that listening is an active process, and that even under ideal circumstances with an interested listener, only about one-third of what is heard is actually listened to, even less if the listener is not interested.

The groups reported risks when information from the OT team was transferred to the PACU team if the sender of information did not have all of the essential information from the surgeon. According to Manser et al, ${ }^{9}$ a shared understanding is an important feature of handover quality. Sandberg and Targama ${ }^{15}$ suggested that people in an organisation must have a shared understanding if cooperation is to be achieved. This involves having both a similar understanding of the collective's work in its entirety and an understanding of their specific roles and competence in the performance of a task. ${ }^{15}$ There is a need for the different professional groups within the OT team and between the OT team and the PACU team to have a shared understanding of the whole so that they can together ensure the patient's continuing care. In the present study, the participants' reflections indicate that there is room for improvement.

The professional groups described strategies for ensuring the quality of handover. One initial strategy is to focus on deviating events. This is in line with one of the recommendations for improving communication in teams made by Flin et $a l^{26}$ who suggested that the message should be as brief as possible, including only the most relevant information owing to the costs of attention and cognitive resources for both the sender and 
the receiver. Another strategy, described by the professional groups, was using a structure for the information that is handed over. This is in line with an integrative review of postoperative handover showing that information transfer, technical errors and high-risk events were positively influenced by the use of structured handover tools. ${ }^{27}$ Communication with high predictability can be said to contain redundancy, which facilitates the receiver's interpretation of the message. ${ }^{28}$ A third strategy was to see the benefits of cooperation between and within the teams, which is in accordance with a previous study. ${ }^{17}$ Moreover, the professional groups thought that having a shared understanding would improve the postoperative handover, which is in line with earlier studies. ${ }^{915}$ Furthermore, the nurse anaesthetists and the PACU nurses wanted written information in front of them; they saw disadvantages associated with electronic patient records, because these records were not in the immediate vicinity of the patient. In line with this, a study by Redley $e t a l^{20}$ showed that clinicians saw difficulties, during postoperative handover, when documents were incomplete or not immediately available. We therefore suggest that postoperative handovers be performed in a structured way, such as when using SBAR, and that the electronic patient records be designed to be user-friendly and placed near the patient.

It is well known that the PACU environment is marked by frequent interruptions, ${ }^{6}{ }^{29}$ and in the present study such interruptions were seen as possibly causing distractions. Nevertheless, both the nurse anaesthetists and PACU nurses mentioned the benefits of the bedside handover, as it increased control of the patient. Results of a study by Frankel $e t a l^{30}$ concerning context, culture and communication during handover suggested that a 'joint focus of attention' has the greatest potential for achieving a high-quality and reliable handover. Such an approach coordinates the sender's and receiver's verbal and visual attention jointly on an artefact. Redundancy in the visual field gives a momentary 'joint focus of attention' using simultaneous inputs. ${ }^{30}$ The bedside handover, described by the nurse anaesthetists and PACU nurses in the present study, has the potential to create a 'joint focus of attention'. However, interruptions interfere with memory and therefore should be minimised. ${ }^{631}$

The professional groups gave different descriptions of the part of the handover that concerned responsibility. Greenberg $e t a l^{32}$ investigated malpractice claims due to communication breakdowns during the preoperative, intraoperative and postoperative period and found that $43 \%$ occurred during handover and that ambiguity about responsibilities was a commonly associated factor. As in a study by Smith and Mishra, ${ }^{5}$ the PACU nurses did not accept taking over responsibility if the handover was not completed. In contrast to the nurse anaesthetists, the anaesthesiologists stated that they did not hand over the responsibility after handover to a PACU nurse. Because ambiguity concerning responsibility seems to be a contributing factor to adverse events, the professional groups' responsibility should be clearly stated.

\section{Strengths and weaknesses of the study}

Previous studies of handovers have taken up the notion that professions involved in postoperative handover might have different perspectives on the handover. We chose focus group interviews with profession homogeneous groups consisting of participants with considerable experience of postoperative handover. One limitation could be the small sample size drawn from two similar hospitals. The number of participants in each group was quite small, which entails the potential risk that data saturation was not reached. However, Krueger and Casey ${ }^{24}$ recommended that a group with fewer participants is preferable when the purpose is to understand an issue or behaviour, when the topic is complex and when the participants' level of experience is high. In the present study, trustworthiness is described and enhanced by the criteria of credibility, dependability, confirmability and transferability. The text was analysed and discussed by two authors (MR and GM); to achieve credibility and dependability, the subcategories and categories were discussed by all coauthors until consensus was reached. ${ }^{33}$ Furthermore, representative quotes from the transcribed text were used to enhance credibility. The first author was familiar with the context investigated, which may have threatened the confirmability. Conducting the analysis together with a coauthor with a different clinical background may have decreased this risk. ${ }^{34}$ The assistant moderator observed the interaction between the participants. All participants had opportunities to voice their opinion about the handover, and everyone agreed on the summary. However, member checking was not used, which is a potential threat to data credibility. We have tried to explain the context as thoroughly as possible to allow the reader to determine the transferability of the present results. With a view to increasing trustworthiness, we have explained the data analysis as thoroughly as possible to meet the criteria of dependability. ${ }^{34}$

\section{CONCLUSION}

The present findings revealed variations in different professionals' views on the postoperative handover. Healthcare interventions are needed that aim to minimise the gap between professionals' perceptions and practices and to achieve a shared understanding. Furthermore, to ensure high-quality and safe care, stakeholders/decision makers need to pay attention to the environment and infrastructure in postanaesthesia care.

Acknowledgements We would like to thank the participants for their contribution to this study.

Contributors All authors (MR, ME, CLS and GM) contributed to the design, interpreted data, drafted and revised the article critically. MR and GM collected the data. Data analysis was primarily conducted by MR and GM, and the data were discussed with all authors (MR, ME, CLS and GM). MR wrote the manuscript under the supervision of ME, CLS and GM. All authors read and approved the final version of the paper. 
Funding This work was supported by the Faculty of Health and Occupational Studies, University of Gävle and by the County Council Gävleborg. It was also supported by the Patient Insurance LÖF and the Swedish Society of Nursing, but these organizations had no role in the design or running of the study.

Competing interests All authors have completed the ICMJE uniform disclosure form at www.icmje.org/coi_disclosure.pdf and declare: MR has received research grants from Patient Insurance LÖF and the Swedish Society of Nursing; there are no other relationships or activities that could appear to have influenced the submitted work.

\section{Patient consent No patient was included in the study.}

Ethics approval The Regional Ethical Review Board in Uppsala, Sweden (reg $\mathrm{n}$. 2011/061).

Provenance and peer review Not commissioned; externally peer reviewed.

Data sharing statement There are no additional data available for data sharing.

Open Access This is an Open Access article distributed in accordance with the Creative Commons Attribution Non Commercial (CC BY-NC 4.0) license, which permits others to distribute, remix, adapt, build upon this work non-commercially, and license their derivative works on different terms, provided the original work is properly cited and the use is non-commercial. See: http://creativecommons.org/ licenses/by-nc/4.0/

(C) Article author(s) (or their employer(s) unless otherwise stated in the text of the article) 2017. All rights reserved. No commercial use is permitted unless otherwise expressly granted.

\section{REFERENCES}

1. Jeffcott SA, Evans SM, Cameron PA, et al. Improving measurement in clinical handover. Qual Saf Health Care 2009;18:272-6.

2. Smith AF, Pope C, Goodwin D, et al. Interprofessional handover and patient safety in anaesthesia: observational study of handovers in the recovery room. Br J Anaesth 2008;101:332-7.

3. Siddiqui N, Arzola C, lqbal M, et al. Deficits in information transfer between anaesthesiologist and postanaesthesia care unit staff: an analysis of patient handover. Eur J Anaesthesiol 2012;29:438-45.

4. Chin GS, Warren N, Kornman L, et al. Transferring responsibility and accountability in maternity care: clinicians defining their boundaries of practice in relation to clinical handover. BMJ Open 2012;2:e000734.

5. Smith AF, Mishra K. Interaction between anaesthetists, their patients, and the anaesthesia team. Br J Anaesth 2010;105:60-8.

6. Randmaa M, Mårtensson G, Swenne CL, et al. An observational study of postoperative handover in anesthetic clinics; the content of verbal information and factors influencing receiver memory. $J$ Perianesth Nurs 2015;30:105-15.

7. Randmaa M, Swenne CL, Mårtensson G, et al. Implementing situation-background-assessment-recommendation in an anaesthetic clinic and subsequent information retention among receivers: a prospective interventional study of postoperative handovers. Eur J Anaesthesiol 2016;33:172-8.

8. Baker DP, Day R, Salas E. Teamwork as an essential component of high-reliability organizations. Health Serv Res 2006;41:1576-98.

9. Manser T, Foster S, Gisin S, et al. Assessing the quality of patient handoffs at care transitions. Qual Saf Health Care 2010;19:e44.

10. Mazzocco K, Petitti DB, Fong KT, et al. Surgical team behaviors and patient outcomes. Am J Surg 2009;197:678-85.

11. Patterson ES, Wears RL. Patient handoffs: standardized and reliable measurement tools remain elusive. Jt Comm J Qual Patient Saf 2010;36:52-61.
12. Cohen MD, Hilligoss PB. The published literature on handoffs in hospitals: deficiencies identified in an extensive review. Qual Saf Health Care 2010;19:493-7.

13. Riesenberg LA, Leitzsch J, Cunningham JM. Nursing handoffs: a systematic review of the literature. Am J Nurs 2010;110:24-34.

14. Møller TP, Madsen MD, Fuhrmann L, et al. Postoperative handover: characteristics and considerations on improvement: a systematic review. Eur J Anaesthesiol 2013;30:229-42.

15. Sandberg J, Targama A. Ledning och förståelse: en förståelsebaserad syn på utveckling av människor och organisationer. Lund: Studentlitteratur 2013;285.

16. Catchpole KR, de Leval MR, McEwan A, et al. Patient handover from surgery to intensive care: using formula 1 pit-stop and aviation models to improve safety and quality. Paediatr Anaesth 2007; $17: 470-8$

17. Currey J, Browne J, Botti M. Haemodynamic instability after cardiac surgery: nurses' perceptions of clinical decision-making. J Clin Nurs 2006;15:1081-90.

18. Nagpal K, Arora S, Abboudi M, et al. Postoperative handover: problems, pitfalls, and prevention of error. Ann Surg 2010;252:171-6.

19. Nagpal K, Arora S, Vats A, et al. Failures in communication and information transfer across the surgical care pathway: interview study. BMJ Qual Saf 2012;21:843-9.

20. Redley B, Bucknall TK, Evans S, et al. Inter-professional clinical handover in post-anaesthetic care units: tools to improve quality and safety. Int J Qual Health Care 2016;28:573-9.

21. The Swedish Society of Nursing. Specialistsjuksköterska inom anestesisjukvård. http://www.swenurse.se/Sa-tycker-vi/ Publikationer/Kompetensbeskrivningar-och-riktlinjer/Specialistsj ukskoterska-inom-anestesisjukvard (accessed 10 Sep 2015).

22. WHO Patient Safety Solutions. volume 1, solution 3. $2007 \mathrm{http}: / /$ www.refworks.com/refgrabit/rw2linkpage.aspx?subscriber $=6107 \&$ user $=1209 \&_{-}=1344860455630$ (accessed 13 Aug 2012).

23. WHO Surgical Safety Checklist. http://www.who.int/patientsafety/ safesurgery/checklist/en/. Accessed 11 Mar 2015

24. Krueger RA, Casey MA. Focus groups: a practical guide for applied research. Thousand Oaks, Calif:: Sage Publications, 2015.

25. Patton MQ. Qualitative research \& evaluation methods. London: SAGE, 2004.

26. Flin RH, O'Connor P, Crichton M. Safety at the sharp end: a guide to non-technical skills. 317. Aldershot, England: Ashgate Publishing Co, 2008.

27. Gardiner TM, Marshall AP, Gillespie BM. Clinical handover of the critically ill postoperative patient: an integrative review. Aust Crit Care 2015;28:226-34.

28. Fiske J. Introduction to communication studies. London: Routledge, 1990.

29. Chen JG, Wright MC, Smith PB, et al. Adaptation of a postoperative handoff communication process for children with heart disease: a quantitative study. Am J Med Qual 2011;26:380-6.

30. Frankel RM, Flanagan M, Ebright P, et al. Context, culture and (non-verbal) communication affect handover quality. BMJ Qual Saf 2012;21(Suppl 1):i121-i128.

31. Li SY, Magrabi F, Coiera E. A systematic review of the psychological literature on interruption and its patient safety implications. J Am Med Inform Assoc 2012;19:6-12.

32. Greenberg CC, Regenbogen SE, Studdert DM, et al. Patterns of communication breakdowns resulting in injury to surgical patients. $J$ Am Coll Surg 2007;204:533-40.

33. Hsieh HF, Shannon SE. Three approaches to qualitative content analysis. Qual Health Res 2005;15:1277-88.

34. Graneheim UH, Lundman B. Qualitative content analysis in nursing research: concepts, procedures and measures to achieve trustworthiness. Nurse Educ Today 2004;24:105-12. 